\title{
PÓS-VERDADE: NOVO OBJETO DE ESTUDO PARA A CIÊNCIA DA INFORMAÇÃO
}

\author{
POST-TRUTH: A NEW RESEARCH OBJECT FOR \\ INFORMATION SCIENCE
}

Carlos Alberto Ávila Araújoa

\begin{abstract}
RESUMO
Introdução: Este texto apresenta os resultados de uma pesquisa sobre a evolução da ciência da informação, seus conceitos e problemáticas, evidenciando como o recente fenômeno da pós-verdade coloca novas questões para a área. Objetivo: Os objetivos se relacionam com a identificação e caracterização do fenômeno da pós-verdade de forma a demonstrar que ele representa uma nova realidade informacional a desafiar as categorias até então existentes na ciência da informação. Metodologia: Revisão de literatura e discussão epistemológica. Resultados: Os resultados apontam a necessidade de a ciência da informação conferir centralidade ao atributo de "verdade" da informação, além de outros já estudados como relevância, recuperação, relação com o conhecimento, entre outros. Conclusões: O fenômeno da pós-verdade se apresenta como o grande desafio contemporâneo da ciência da informação, a exigir maior aprofundamento em sua compreensão e o desenvolvimento de ações e estratégias para lidar com ele.
\end{abstract}

Descritores: Epistemologia da ciência da informação. Pós-verdade. Informações falsas.

\section{INTRODUÇÃO}

As diferentes disciplinas científicas estudam diversos fenômenos e realidades empíricas. Com o passar dos anos, cada ciência vai modificando seus conceitos, suas teorias, seus métodos de pesquisa. Isso ocorre, em parte, pela própria evolução dos conhecimentos científicos: teorias vão sendo refutadas, conceitos refinados, métodos substituídos por outros. Mas, em parte, isso ocorre também por mudanças da própria realidade: os fenômenos vão se alterando, adquirindo novos aspectos, novas dimensões, manifestações até então inéditas.

\footnotetext{
a Pós-doutor pela Universidad de Salamanca (2019), e pela Universidade do Porto (2011). Docente da Escola de Ciência da Informação da Universidade Federal de Minas Gerais (UFMG). E-mail: casalavila@yahoo.com.br
} 
Essa realidade vale para todas as disciplinas científicas. Vale, também, para a ciência da informação. Surgida na década de 1960, ela nasceu profundamente relacionada com a dinâmica da chamada "explosão da informação" que se verificou após a II Guerra Mundial, com o aumento exponencial da produção em ciência e tecnologia. Preocupada exclusivamente com o ambiente científico e com o desenvolvimento de estratégias para a recuperação da informação e as possibilidades de automação de sua organização, a área acabou englobando nos anos seguintes questões ligadas aos ambientes empresarial, político, e depois social e cultural, entre outros.

Nos últimos cinco anos, contudo, profundas mudanças na própria realidade empírica, isto é, no campo dos fenômenos informacionais, relacionadas com as tecnologias digitais, mas não só, promoveram uma série de desafios que colocam em xeque as categorias de pensamento até então existentes no campo da ciência da informação.

Entre essas mudanças destacam-se a informação pervasiva, isto é, a informação enquanto entidade e/ou processo presente em todas as nossas atividades, sejam elas profissionais, empresariais, culturais, educacionais, esportivas, médicas, amorosas, etc, de uma maneira ou em uma escala inédita até então, relacionada a aparelhos ou dispositivos tão diferentes como computadores, telefones celulares, casas, carros ou objetos, tendo relação inclusive com o surgimento da chamada internet das coisas. Um modelo de entendimento da informação como sendo um fenômeno em que usuários buscariam informação em sistemas de informação (o chamado "paradigma do balcão", construído sob a ideia de que acesso ou recuperação eram o centro das atividades e serviços informacionais) vai se mostrando inadequado para essas novas realidades. As dinâmicas informacionais atuais são de uma complexidade crescente: mais do que buscar e acessar, as pessoas querem produzir, compartilhar, comentar, etiquetar informação.

Ligado a isso está o fenômeno conhecido como big data, que se relaciona não apenas com a produção, em escala cada vez mais gigantesca, de informação, e do impacto dessa informação na nossa vida, mas também com a própria maneira como a informação é produzida. Esse fenômeno se relaciona 
com o fato de que, cada vez mais, há conjuntos de dados gerados de maneira não intencional, não programada, pelas pessoas - o que questiona os modelos conceituais da ciência da informação que imaginavam um sujeito enviando uma mensagem para alguém. Agora, temos sistemas que estão capturando nossos passos, nossos trajetos, nossos indicadores biométricos, e estão transformando tudo isso em conjuntos de dados que são apropriados e utilizados com diferentes fins, desde a segurança e a comodidade à vigilância e controle político, representando também um desafio para a privacidade dos nossos dados.

Merecem destaque ainda a própria velocidade da informação e de necessidade de atualização, quando se medem em minutos ou segundos a defasagem de conhecimento das pessoas sobre determinado fato ou assunto que pode estar ocorrendo num contexto local ou mesmo em países distantes. $O$ grande volume de informação que chega instantaneamente para os sujeitos, em formatos, linguagens e suportes muito diferenciados como textos, imagens, sons, imagens em movimento e outros derivados destes. Apenas para se pensar em um exemplo, há relativamente poucos anos as famílias se juntavam para assistirem juntas à televisão, hoje numa casa com razoáveis recursos financeiros cada pessoa possui seu smartphone e nele individualmente navega pela internet, assiste a filmes por serviços de streaming, executa listas de músicas e muito mais num consumo bastante individualizado de informação.

Em meio a todos esses fatos, há um fenômeno informacional atual que vem desafiando a ciência da informação: a pós-verdade. Ligado aos fenômenos apresentados até aqui, intimamente relacionado com as tecnologias digitais, a pós-verdade expressa um conjunto de fatos e processos até então inéditos, que ainda estão sendo compreendidos e mapeados, e cuja efetiva análise e entendimento demanda ferramentas teóricas, conceituais e metodológicas inovadoras no campo da ciência da informação.

O objetivo deste texto é apresentar os resultados de uma pesquisa conduzida com esse objetivo. Tais resultados são apresentados a seguir em três momentos. Inicialmente, faz-se uma apresentação da evolução das questões e objetos de pesquisa na ciência da informação. A seguir, apresenta-se o fenômeno da pós-verdade, suas causas, conformações e consequências. Ao 
final, são confrontadas essas duas questões, apresentando-se uma nova agenda de pesquisa para o campo da ciência da informação.

\section{A EVOLUÇÃO DAS PROBLEMÁTICAS NA CIÊNCIA DA INFORMAÇÃO}

De acordo com as teorias mais recentes da ciência da informação (HJORLAND, 2018a; HJORLAND, 2018b; BAWDEN; ROBINSON, 2012), estudar informação é estudar uma tensão entre dois polos: a dimensão coletiva, social, de um lado, e a dimensão individual, pessoal, de outro. Cada um de nós tem uma maneira de produzir e de consumir informação, que é única, mas essa maneira também é devedora do social, da interiorização de modelos sobre que fontes devem ser privilegiadas, ser descartadas, ser valorizadas, conforme os modelos com que os diferentes grupos e comunidades (profissionais, étnicas, geracionais, nacionais, entre outras) lidam com a informação. Essas formas de se lidar com a informação são parcialmente únicas, parcialmente coletivas, e o desafio da ciência da informação é exatamente detectar isso, determinar o que é informação para determinado grupo, o que é relevante, como se constroem socialmente os critérios de relevância, de pertinência, de exatidão, de atualidade, entre outros. Assim se constroem os regimes de informação (quais são as fontes de informação mais importantes, mais valiosas, melhores, atuais, ultrapassadas, de um contexto) e também as práticas dos sujeitos que se apropriam, constroem e desconstroem essas regras, esses padrões, ao tomarem decisões, escolherem, indicarem, influenciarem outras pessoas.

Nem sempre, contudo, foi assim. A ciência da informação nasceu na Inglaterra e nos Estados Unidos, no período imediatamente posterior à II Guerra Mundial, vinculada com a importância que a informação possuía, neste contexto, para o desenvolvimento científico e tecnológico no período da guerra fria. Nesse sentido, "informação" era entendida em um sentido bastante específico, enquanto informação científica e tecnológica, e seu estudo se dava dentro de uma lógica essencialmente governamental e militar, isto é, os objetivos com o estudo da informação eram, antes mesmo de serem propriamente científicos, pragmáticos, relacionados a um contexto de competição entre países pela hegemonia no cenário internacional. Estudar a informação era compreender e 
mapear a produção, circulação e uso da informação científica e tecnológica (e apenas desta) para se pensar em instrumentos de seu processamento para garantir maior rapidez, menor custo, maior exatidão em sua transferência dentro da comunidade científica e desta para os setores estratégicos dos ambientes governamental e militar (COLL-VINENT, 1984; DEBONS; HORNE; CRONENWETH, 1988; LINARES COLUMBIÉ, 2005). Tratava-se de uma maneira muito específica de conhecer (a partir de um conjunto de interesses) e da delimitação de algo muito específico a ser conhecido - aquilo que era considerado objeto de estudo da ciência da informação.

Desenvolveu-se aí uma ciência do controle da informação, do desenvolvimento de técnicas para seu processamento ótimo num contexto da competitividade entre países por meio do desenvolvimento de seus sistemas de informação científica (DAVIS; SHAW, 2001). O modelo teórico desta abordagem, conhecido como "paradigma dos sistemas" ou paradigma físico, que pressupõe o estudo dos sistemas de informação isolados da vida social e dos usuários, basicamente a partir de medidas quantitativas de desempenho de recuperação da informação (BAWDEN; ROBINSON, 2012). Tal modelo é resultado da complementação de duas perspectivas. A primeira é a da teoria matemática da comunicação de Shannon e Weaver, que entende a comunicação como um processo de envio de mensagens de um emissor a um receptor, cabendo à ciência da informação atuar na otimização do transporte dessas mensagens por meio do processamento e da recuperação da informação. O segundo é o modelo sistêmico derivado da tradição de estudos iniciados com os experimentos realizados Cranfield Institute of Technology nas décadas de 1950 e 1960, em que os sistemas de informação são avaliados em termos de seus atributos objetivos e suas performances em recuperação da informação (HJORLAND, 2018a).

Nas décadas seguintes, desenvolveu-se na ciência da informação uma perspectiva cognitivista, centrada nos usuários. Esse movimento representou um deslocamento da mesma lógica de pesquisa dos ambientes governamental e militar para o âmbito do setor industrial e empresarial, com demandas de eficácia de gestão, operação e controle (DEBONS; HORNE; CRONENWETH, 1988). A 
novidade, do ponto de vista conceitual, foi a introdução de uma perspectiva orientada não mais para os sistemas, mas sim para os usuários ou clientes (HJORLAND, 2018a). Com isso, deu-se o estudo dos processos cognitivos humanos e sua modelização, com o objetivo de desenvolver sistemas de informação que pudessem replicar tais processos, de modo que o foco dos estudos eram os indivíduos se relacionando com a informação e a manifestação de suas necessidades e os procedimentos para resolução destas necessidades (BAWDEN; ROBINSON, 2012; GILCHRIST, 2009).

No final do século $X X$, iniciou-se a construção de uma outra perspectiva de estudos da informação, apresentada no início deste tópico. Linares Columbié (2005) destaca a novidade deste movimento como sendo uma outra epistemologia da ciência da informação desde o estudo da sociedade e da cultura. Cronin (2008) fala de uma virada sociológica na ciência da informação, em seguimento à virada cognitiva da década de 1980. Hjorland (2018b) menciona as recentes visões orientadas desde uma perspectiva social e cultural. Bawden e Robinson (2012) indicam um paradigma sócio-cognitivo, inspirado na epistemologia social de Shera e na análise de domínio de Hjorland, que busca analisar um nível de análise mais amplo que o indivíduo (os grupos sociais, comunidades, países) bem como outras problemáticas além da cognição (nível apenas mentalista dos fenômenos informacionais), numa tendência a articular os níveis individual e coletivo da informação. Apontam ainda que a posição epistemológica da teoria crítica, oriunda das humanidades e das ciências sociais, deverá "ter mais impacto na ciência da informação no futuro" (BAWDEN; ROBINSON, 2012, p. 41, tradução nossa). Essa terceira abordagem tem expressões em teorias como a dos regimes de informação, análise de domínio, práticas informacionais, folksonomias, altmetria, entre outras, voltadas para 0 caráter socialmente construído da informação e suas imbricações com as dimensões políticas, econômicas, culturais, jurídicas, tecnológicas e outras das sociedades nas quais os fenômenos informacionais existem e se constituem.

Em sua evolução ao longo destas seis décadas de existência, a ciência da informação acumulou consideráveis conhecimentos sobre os fenômenos informacionais. Entre esses conhecimentos está, em primeiro lugar, a percepção 
de que o conhecimento não é apenas um processo de acúmulo de dados, de inserção de dados na mente dos sujeitos; trata-se de um processo dialético, no qual cada sujeito faz dialogarem os novos conhecimentos com aqueles que ele já possui - duvidando de alguns, recusando outros, adotando ainda outros. Em segundo lugar, a compreensão de que sujeito não são apenas mentalistas, apenas "cérebros consumindo conhecimento" - os sujeitos agem na sociedade, estudam, trabalham, votam, passeiam, e integram a todo momento os conhecimentos de que dispõem a essas atividades cotidianas, frequentes, no decorrer de sua existência. É preciso integrar o estudo das dinâmicas informacionais ao estudo das demais dinâmicas da nossa vida.

Em terceiro lugar, descobriu-se que os processos informacionais não são compostos apenas por ações de busca e de recuperação da informação. São também de produção, disseminação, compartilhamento, etiquetagem, etc. Junto a isso, um quarto achado das pesquisas é a noção de que os processos informacionais não são unicamente individuais, idiossincráticos, mas são também de natureza intersubjetiva, e é preciso desenvolver estratégias para capturar esse duplo movimento (o individual e o social).

Além disso, para se estudar informação, não é suficiente entender o que acontece no interior do sistemas, não basta entender o que se passa com 0 aplicativo, ou com a biblioteca ou um serviço de informação - as realidades dos sistemas são atravessadas por elementos dos contextos sócio-históricos, políticos, culturais, jurídicos. Para capturar os fenômenos informacionais na sua complexidade é preciso inserir aquilo que se passa nos sistemas de informação nos contextos nos quais eles existem. Por fim, a principal evidência dos estudos informacionais permite concluir que informação não é apenas um processo de transporte de dados, não basta determinar de onde partiram certas mensagens, as transformações que elas sofreram e onde chegaram (bem como os instrumentos que atuaram nesse processo). Estudar informação é analisar em que medida a informação é também um processo de constituição da cultura, da memória coletiva e da identidade dos indivíduos.

Essa dinâmica dos conhecimentos e objetos na ciência da informação se manifestaram em suas diferentes subáreas (gestão da informação, organização 
da informação, usuários, estudos métricos, sociedade da informação) gerando uma imensa acumulação de conhecimentos sobre a realidade informacional (HJORLAND, 2018a; BAWDEN; ROBINSON, 2012).

\section{PÓS-VERDADE: CARACTERÍSTICAS DE UM FENÔMENO INFORMACIONAL CONTEMPORÂNEO}

De acordo com Santaella (2019), a expressão "pós-verdade" já havia sido utilizada por Steve Tesich em 1992, para referir-se a questões sobre a Guerra do Golfo, e figurou num título de um livro pela primeira vez na obra de Ralph Keyes publicada em 2004. Foi em 2016, contudo, que ela foi indicada como a palavra do ano pelo Dicionário Oxford, designando as "circunstâncias nas quais fatos objetivos são menos influents na formação da opinião pública do que apelos à emoção e à crença pessoal" (SANTAELLA, 2019, p. 7).

Existe muita discussão sobre o que é pós-verdade. Existe uma grande confusão entre o termo e a expressão "fake news", por exemplo. São fenômenos relacionados, mas não são o mesmo. Há quem defenda que a expressão não tem sentido, pois mentiras sempre existiram - como se pós-verdade fosse sinônimo de mentira. De fato, mentiras sempre existiram, disseminação de informações falsas é algo que sempre ocorreu, mas há um fato novo, um fenômeno novo, naquilo que pesquisadores do mundo inteiro, de várias áreas, vêm chamando de pós-verdade. A expressão pós-verdade surgiu para caracterizar o momento contemporâneo em que há uma gigantesca disseminação de informações falsas, que estão moldando a tomada de decisão das pessoas (na hora de votar, de decidir pela adesão ou não a blocos econômicos, de tomar cuidados com a saúde), em quantidade e velocidade nunca vistas e, também, de maneira anônima, apócrifa, sem identificação de autoria. Mas a novidade é que há, por parte das pessoas, um desprezo, um desdém, um desinteresse pela veracidade das informações recebidas e compartilhadas. As pessoas recebem a informação, muitas vezes sabem que é falsa, mas elas compartilham assim mesmo, elas não se importam. Esse é o fenômeno novo a não veracidade da informação se torna banal, se torna naturalizada. Nunca na história houve tanta possibilidade de se checar se uma 
informação é falsa ou verdadeira. Mas as pessoas não fazem isso, não checam, não verificam. Esse é o fato novo que tem desafiado os pesquisadores de várias disciplinas científicas.

O que é chamado hoje de "pós-verdade" refere-se a uma conjuntura produzida por diversos fatos ou fenômenos que já vinham acontecendo há décadas (ou séculos, em alguns casos), mas que se relacionaram ou interagiram de uma determinada maneira somente nos últimos anos. Como colocado por McIntyre, a pós-verdade não surgiu antes, ela "esperou a tempestade perfeita que teria outros fatores como o viés partidarista extremo e os 'silos' das redes sociais que surgiram no começo dos anos 2000" (McINTYRE, 2018, p. 68, tradução nossa). Diversos autores (McINTYRE, 2018; KAKUTANI, 2019; WILBER, 2018; SANTAELLA, 2019) dedicaram-se a estudar as causas ou fatores que conduziram à pós-verdade.

O primeiro destes fatores é o negacionismo científico: um fenômeno em que a autoridade da ciência passou a ser questionada por pessoas comuns, num processo motivado por interesses econômicos de determinados grupos empresariais e corporativos. O marco de origem desse processo se deu na década de 1950, nos Estados Unidos, quando diversos estudos científicos começaram a associar o fumo ao câncer. Grupos empresariais da indústria do tabaco criaram, então, a Tobacco Industry Research Committee, com o objetivo de financiar "cientistas" que demonstrassem o contrário, que não havia evidências conclusivas dos males causados pelo fumo. $\mathrm{O}$ objetivo principal não era invalidar as conclusões dos cientistas de então, mas semear a dúvida junto ao público, gerar confusão. Num estudo clássico sobre o assunto, Oreskes e Conway explicam que, para esse comitê, a dúvida era o seu produto. Os autores apontam que, daí em diante, a estratégia foi utilizada por vários atores empresariais e políticos em relação a outros temas como o inverno nuclear, a chuva ácida, o buraco na camada de Ozônio e o aquecimento global (McINTYRE, 2018).

O segundo fator se relaciona com determinadas características cognitivas humanas, que alguns chamam de viés cognitivo ou de dissonância cognitiva. $O$ ser humano tem uma tendência a recusar os fatos que contradizem suas crenças 
ou ideias, aquilo em que acredita, tem uma tendência a buscar o conforto psíquico. Mclntyre (2018) aponta três estudos clássicos em psicologia social conduzidos nos Estados Unidos, nas décadas de 1950 e 1960, que demonstraram essa questão. O primeiro deles é a teoria da dissonância cognitiva de Festinger, segundo a qual buscamos harmonia entre nossas crenças e ações. O segundo é a teoria da conformidade social de Asch, que postula que temos tendência a ceder à pressão social por nosso desejo de estar em harmonia com os outros. O terceiro é o estudo do viés de confirmação conduzido por Watson, que identificou nossa tendência a dar mais peso às informações que confirmam nossas crenças pré-existentes. $O$ autor apresenta também estudos recentes sobre a questão, expressos em dois conceitos: efeito contraproducente (fenômeno em que a apresentação de uma informação verdadeira para uma pessoa, que entra em conflito com suas crenças em fatos falsos, faz com que a pessoa creia nesses fatos com mais força ainda) e o efeito Dunning-Kruger (fenômeno no qual nossa falta de capacidade para fazer algo faz com que superestimemos nossas habilidades reais). Tais elementos do viés cognitivo fazem com que as pessoas sejam propensas a formar suas crenças sem ter em conta a razão e as evidências.

O terceiro fator normalmente apontado como propiciador da pós-verdade é o fenômeno da desintermediação da informação:

Tradicionalmente, na era hegemônica da comunicação de massas, as notícias eram fabricadas em fontes restritas, relativamente confiáveis na medida em que deveriam seguir práticas baseadas em códigos estritos de deontologia, ou seja, um conjunto de deveres, princípios e normas adotadas por um determinado grupo social, nesse caso, a profissão de jornalista. A partir da emergência da internet, da cultura digital e das redes sociais, surgiram novos modos de publicar, compartilhar e consumir informação e notícias que são pouco submetidos a regulações ou padrões editoriais (SANTAELLA, 2019, p. 30).

Assim, verifica-se uma profusão de conteúdos baseados em opinião, muitas vezes de pessoas sem qualquer conhecimento no assunto, que também está relacionada a esse processo. Não que os meios de comunicação de massa tenham sempre dito apenas a verdade, mas eles representavam instituições, com possibilidade de serem responsabilizados por seus conteúdos, diferente do que ocorre nos ambientes digitais atuais nos quais conteúdos falsos, boatos e 
distorções são compartilhados. Agora, o que se tem são notícias, fotos, sem link válido, que imitam a informação institucional, peças individualizadas, isoladas, sem contexto, sem data, sem autoria (MAGALLÓN ROSA, 2019). Associa-se a esse fenômeno uma certa desvalorização das instituições e dos especialistas, naquilo que Keen (2008) chamou de um "culto do amadorismo".

Há um quarto fenômeno, diretamente associado a este, que é o crescimento das redes sociais e de dois fatos relacionados a isso, o efeito bolha e a disseminação subterrânea de informação. As redes sociais se tornaram o ambiente privilegiado a partir do qual as pessoas recebem notícias e informações do mundo. E elas são construídas a partir de algoritmos que selecionam o que provavelmente as pessoas querem ou o que concorda com o ponto de vista delas, num fenômeno conhecido como "efeito bolha". Outra questão é a existência de redes sociais em que mensagens são disparadas em massa diretamente para os aparelhos das pessoas, sem que se possa monitorar ou se contrapor a elas, numa lógica "subterrânea" de disseminação de informação.

Por fim, há um último fator apontado muitas vezes, que é o questionamento da ideia de verdade promovido pelo movimento pós-moderno ao longo da segunda metade do século XX (KAKUTANI, 2019). O movimento pós-modernista desenvolveu-se ao longo do século $\mathrm{XX}$ como um movimento artístico, cultural e também filosófico. Entre suas características está 0 questionamento da ideia de existência de uma verdade absoluta, única, ou seja, não existiria uma resposta absolutamente correta sobre o que cada elemento da realidade significa. A denúncia de que qualquer declaração de verdade seria um ato autoritário, porque sempre ideológica, acabou sendo uma crítica sequestrada por movimentos políticos para dizer que tudo seria ideológico e, portanto, não haveria "verdade", apenas "fatos alternativos".

O fenômeno da pós-verdade efetiva-se a partir de certas características. Santaella (2019, p. 33) apresenta três grandes conjuntos de problemas em que se manifesta a pós-verdade: o conteúdo deliberadamente falso, as mensagens enganadoras que não são necessariamente falsas, e os memes que não são nem verdadeiros nem falsos, mas produzem impressões negativas ou incorretas. Ela aponta também outras condições de ocorrência do fenômeno, como o fato 
de as redes sociais provocarem mais efeito bolha do que os motores de busca, ou a importância da popularidade, sobre o qual estudos mostram que a informação falsa tem mais propensão a ser difundida do que a verdadeira. $A$ atuação totalitária e empobrecedora da experiência dos indivíduos também foi constatada e caracterizada por Noble (2018).

Já Aparici e García Martín (2019) argumentam que a pós-verdade se manifesta a partir de oito aspectos: os clickbait (inserção de títulos sensacionalistas para que os usuários acessem o conteúdo, com o objetivo de gerar tráfico e ter benefícios com publicidade), o conteúdo patrocinado( emissão de publicidade para parecer-se com conteúdo informativo), a sátira (uso de conteúdos fictícios de paródia com intenção de que as pessoas tomem a informação como correta), o conteúdo partidário (interpretações parciais da realidade mascaradas por aparência de neutralidade), as teorias da conspiração (fundamentadas em histórias que tentam, de forma simples, explicar realidades complexas como resposta ao medo e à incerteza), a pseudociência (negação de fatos cientificamente comprovados mediante interpretações parciais e interessadas), a desinformação (mescla de fatos reais e conteúdo falso, como falsa atribuição de autoria ou imagem) e as fake news (conteúdos inteiramente falsos e inventados, fabricados e propagados deliberadamente para enganar as pessoas com objetivos políticos e econômicos).

Entre as consequências da pós-verdade normalmente são elencadas o enfraquecimento da democracia, o crescimento de regimes políticos autoritários, o extremismo, a polarização e a difusão da cultura do ódio.

Fukuyama (2019) entende a era atual como um período de ressentimento e aponta a eleição de Trump como maior símbolo disso, na medida em que ele representa uma tendência geral da política internacional. Conforme o autor, "outros líderes contemporâneos que podem ser incluídos nesta categoria são Vladimir Putin na Rússia, Recep Tayyip Erdogan na Turquia, Viktor Orbán na Hungria, Jaroslaw Kaczynsi na Polônia e Rodrigo Duterte nas Filipinas" (FUKUYAMA, 2019, p. 12, tradução nossa).

Eatwell e Goodwin (2019) chamam esse fenômeno de "nacionalpopulismo", apresentando uma lista de líderes políticos que se utilizam de 
estratégias de disseminação sistemática de informações falsas. Nesta lista estão os mesmos nomes mencionados por Fukuyama, mas os autores incluem "outras manifestações importantes, como a vitória de Jair Bolsonaro nas eleições presidenciais do Brasil em 2018" (EATWELL; GOODWIN, 2019, p. 11).

Os casos mencionados acima são todos relevantes, pois evidenciam vitórias eleitorais de pessoas com tendências autoritárias e, no caso da discussão empreendida aqui, atores que desprezam a verdade. Trump é o caso mais exemplar, afinal, representa o país que é a maior economia e a maior potência militar do planeta. Wilber (2018) aponta inclusive que Trump fez da mentira sua estratégia política.

Entre as consequências perigosas da vigência do fenômeno da pósverdade, Kakutani (2019) retoma os argumentos de Hannah Arendt, que defende que o sujeito ideal para um governo totalitário é aquele para quem a distinção entre fato e ficção, verdadeiro e falso, deixa de existir. Para ela, portanto, o perigo último da pós-verdade é a consolidação dos populismos e fundamentalismos, que, por meio da destruição da própria ideia de "verdade", destroem também a democracia e impõem o medo e o ódio sobre o debate racional.

Wilber (2018) situa a pós-verdade no âmbito de uma mudança no quadro geral de valores das sociedades contemporâneas. Para ele, teria havido um fracasso do projeto vanguardista iniciado com as revoluções culturais na década de 1960, marcado pelas ideias de pluralidade, relativismo, pós-modernismo, diversidade, inclusão, tolerância, direitos humanos, igualdade das pessoas. $O$ autor destaca o relativismo da noção de verdade do pensamento pós-moderno e a cultura do narcisismo ("o que eu quero que seja verdade se converte em verdade") como os principais responsáveis pela crise de legitimidade desse projeto e o nascimento do que chama de "cultura da pós-verdade", marcada por um retorno ao etnocentrismo, uma política de identidade de modo ativo e agressivo. E aponta o incremento da internet e das redes sociais como um propulsor desse processo, uma vez que a promessa original delas, de uma humanidade global unificada e cooperativa, teria dado lugar ao anonimato do intercâmbio online com tendências carregadas de agressividade, narcisismo, ódio e crenças etnocêntricas (sexismo, racismo, xenofobia, fanatismo). 
Uma outra forma de enxergar o problema é apresentada por Broncano (2019) a partir de sua proposta de uma epistemologia política, na qual articula as questões informacionais (informação e conhecimento como fontes de energia do nosso tempo) às questões políticas (uma compreensão de que tudo o que afeta nossas vidas, o preço da conta de luz, os agrotóxicos nos alimentos, a inflação, são resultado de decisões políticas). Seu objetivo é analisar uma sociedade vendo quem, como e o que se conhece e, paralelamente, quem, como e o que se ignora. A epistemologia política é, assim, o estudo do conhecimento, sua distribuição justa ou injusta na sociedade, numa proposta inspirada na ideia de "estrutura básica" de Rawls (a repartição de bens materiais e imateriais na sociedade) para se pensar numa topografia do conhecimento e da ignorância que organizam uma sociedade.

Broncano situa sua problemática informacional (ou do conhecimento) às questões políticas a partir do ideal de democracia deliberativa de Habermas: um modelo em que os cidadãos, utilizando a razão, exercem uma ação comunicativa de argumentação para, por meio do debate, influir nos rumos do sistema político. Essa seria a diferença entre uma sociedade (usando a razão para a deliberação democrática) e uma horda. Nesse sentido, ele detecta que a democracia deveria estar baseada na "verdade" e não simplesmente em opiniões e crenças. É aí que ele situa a problemática da pós-verdade, causada pelo avanço da polarização e isolamento nas bolhas, da diminuição do jornalismo de investigação e aumento do sensacionalismo e da lógica das redes sociais em que o objetivo é ter curtidas e compartilhamentos e não o aumento do conhecimento sobre a realidade.

\section{A CIÊNCIA DA INFORMAÇÃO NA ERA DA PÓS-VERDADE}

O confronto entre os dois quadros de referência apresentados acima nos coloca uma questão: o que precisa ser modificado na ciência da informação para que ela esteja efetivamente preparada para estudar a pós-verdade?

Pensando nos diferentes momentos conceituais pelos quais a ciência da informação passou, evidencia-se que o aparato conceitual formulado em suas primeiras décadas de existência, voltado para as questões de recuperação e automatização, fornece pouco instrumental para se entender adequadamente as 
dinâmicas da pós-verdade. Pode-se dizer o mesmo da perspectiva cognitiva que se desenvolveu nas duas décadas seguintes, centradas na experiência cognitiva do indivíduo, nas estratégias de busca e uso para superar as lacunas de conhecimento. As perspectivas mais atuais, centradas na constituição social da informação, bem como nos efeitos da informação nas diferentes esferas ou dimensões da vida humana, se mostram claramente mais aptas a contribuir com elementos para a compreensão da pós-verdade. Falta, ainda, um elemento central: atribuir a efetiva centralidade do atributo de "verdade" para a informação. Tal atributo foi, de certa forma, neglicenciado pela ciência da informação durante toda a sua existência, exatamente por não ter se constituído como um problema, como uma questão relevante.

É importante destacar, portanto, que pós-verdade não é sinônimo de circulação de informação falsa, nem mesmo de processamento de dados, pelas pessoas, para o preenchimento de lacunas cognitivas. A pós-verdade é uma cultura, uma mentalidade, um ethos, por meio do qual se manifesta um desprezo, um desdém pela verdade, impactando de maneira decisiva todos os modos de existência e processos que incidem sobre a informação. A informação passa a ser utilizada para semear dúvidas e aumentar a desconfiança nas instituições (MAGALLÓN ROSA, 2019).

Há os que atuam de maneira espontânea nesse processo e, também, grupos políticos e econômicos que atuam planejando, estimulando e se aproveitando desse fenômeno, com consequências gravíssimas para a própria sobrevivência da democracia, da ciência e, em tempos de disseminação de coronavirus e crescimento da doença Covid 19, para a própria sobrevivência da humanidade. Em plena pandemia, circulam pelas redes sociais informações sobre métodos falsos de cura, negacionismo dos casos da doença, subnotificação de casos e taxas de transmissão, bem como apologia a líderes políticos e religiosos que teriam mais condições de lidar com a doença do que a ciência. O fenômeno da pós-verdade se apresenta, assim, como o grande desafio para a ciência da informação nos tempos atuais. 


\section{REFERÊNCIAS}

APARICI, R.; GARCÍA-MARÍN, M. (Coords). La posverdad: una cartografia de los médios, las redes y la política. Barcelona: Gedisa, 2019.

BAWDEN, D.; ROBINSON, L. Introduction to information science. Londres: Facet, 2012.

BRONCANO, F. Puntos ciegos: ignorancia pública y conocimiento privado. Madrid: Lengua de Trapo, 2019.

COLL-VINENT, R. Ciencia documental: princípios y sistemas. Barcelona: Mitre, 1984.

CRONIN, B. The sociological turn in information science. Journal of Information Science, v. 34, n. 4, 2008, p. 465-475.

DAVIS, C.; SHAW, D. Introduction to information science and technology. Medford: Information Today, 2001.

DEBONS, A.; HORNE, E.; CRONENWETH, S. Information science: an integrated view. Boston: G. K. Hall, 1988.

EATWELL, R.; GOODWIN, M. Nacionalpopulismo: por qué está triunfando y de qué forma es un reto para la democracia. Barcelona: Península, 2019.

FUKUYAMA, F. Identidad: la demanda de dignidad y las políticas de resentimiento. Barcelona: Deusto, 2019.

GILCHRIST, A. (Ed.). Information science in transition. Londres: Facet, 2009.

HJORLAND, B. Library and information science (LIS), Part I. Knowledge Organization, v. 45, n. 3, 2018a, p. 232-254.

HJORLAND, B. Library and information science (LIS), Part 2. Knowledge Organization, v. 45, n. 4, 2018b, p. 319-338.

KAKUTANI, M. La muerte de la verdad: notas sobre la falsedad en la era Trump. Barcelona: Galáxia Gutemberg, 2019.

KEEN, A. O culto do amadorismo. Lisboa: Guerra e Paz, 2008.

LINARES COLUMBIÉ, R. Ciencia de la información: su história y epistemología. Santa Fé: Rojas Eberhard, 2005.

MAGALLÓN ROSA, R. Unfaking news: cómo combatir la desinformación. Madrid: Pirámide, 2019. 
McINTYRE, L. Posverdad. Madrid: Cátedra, 2018.

NOBLE, S. U. Algorithms of oppression: how search engines reinforce racism. Nova lorque: New York University Press, 2018.

SANTAELLA, L. A pós-verdade é verdadeira ou falsa? Barueri: Estação das Letras e Cores, 2019.

WILBER, K. Trump y la posverdad. Barcelona: Kairós, 2018.

\title{
POST-TRUTH: A NEW RESEARCH OBJECT FOR INFORMATION SCIENCE
}

\begin{abstract}
Introduction: This text presents the results of a research on the evolution of information science, its concepts and problems, showing how the recent phenomenon of post-truth poses new questions for the area. Objective: The objectives are related to the identification and characterization of the phenomenon of post-truth in order to demonstrate that it represents a new informational reality to challenge the categories previously existing in information science. Methodology: Literature review and epistemological discussion. Results: The results point to the need for information science to give centrality to the "truth" attribute of information, in addition to others already studied such as relevance, retrieval, relationship with knowledge, among others. Conclusions: The phenomenon of the post-truth presents itself as the great contemporary challenge of information science, requiring greater depth in its understanding and the development of actions and strategies to deal with it.
\end{abstract}

Descriptors: Epistemology of information science. Post-truth. Fake news.

\section{POSVERDAD: UN NUEVO OBJETO DE ESTUDIO PARA LA CIENCIA DE LA INFORMACIÓN}

\begin{abstract}
RESUMEN
Introducción: Este texto presenta los resultados de una investigación sobre la evolución de la ciencia de la información, sus conceptos y problemas, y muestra cómo el fenómeno reciente de la posverdad plantea nuevas preguntas para el área. Objetivo: Los objetivos están relacionados con la identificación y caracterización del fenómeno de la posverdad para demostrar que representa una nueva realidad informativa que desafía las categorías previamente existentes en la ciencia de la información. Metodología: revisión de la literatura y discusión epistemológica. Resultados: Los resultados apuntan a la necesidad de que la ciencia de la información dé centralidad al atributo de "verdad" de la información, además de otros ya estudiados, como relevancia, recuperación, relación con el conocimiento, entre otros. Conclusiones: El fenómeno de la posverdad se presenta como el gran desafío contemporáneo de la ciencia de la información, que requiere una mayor profundidad en su comprensión y el desarrollo de acciones y estrategias para enfrentarlo.
\end{abstract}


Descriptores: Epistemología de la ciencia de la información. Posverdad. Informaciones falsas.

Recebido em: 02.04.2020

Aceito em: 08.02.2021 